\title{
Abnormal Uptake Kinetics
}

National Cancer Institute

\section{Source}

National Cancer Institute. Abnormal Uptake Kinetics. NCI Thesaurus. Code C87022.

An artifact that results when an imaging agent is not absorbed or metabolized at the expected rate. 